\title{
Organizational Climate and Work Addiction in Shahid Sadoughi University of Medical Sciences, 2014: a Case Study
}

\author{
Noora Rafiee ${ }^{1}$, Mohammad Amin Bahrami ${ }^{2}$, Vahid Zare ${ }^{3}$, Mahan Mohammadi ${ }^{4}$
}

${ }^{1}$ M.Sc. of Health Care Management, Department of Health Care Management, School of Health, Shahid Sadoughi University of Medical Sciences, Yazd, Iran

${ }^{2}$ Assistance Professor, Ph.D. of Health Care Management, Department of Health Care Management, School of Health, Shahid Sadoughi University of Medical Sciences, Yazd, Iran

${ }^{3}$ M.Sc. Student of Health Care Management, Department of Health Care Management, School of Health, Shahid Sadoughi University of Medical Sciences, Yazd, Iran

${ }^{4}$ M.Sc. of Health Care Management, Department of Health Care Management, School of Management and Medical Informatics, Isfahan University of Medical Sciences, Isfahan, Iran

\section{Type of article: Original}

\begin{abstract}
Introduction: The occupational nature of employees in headquarters units of the University requires them to deal with support issues. Thus, there is some pressure on these employees to complete their assignments on time so that employees in the line units can accurately and expeditiously perform their duties. As a result, work addiction behaviors are sometimes observed among the headquarters personnel. Considering the importance of work addiction and recognizing the factors that intensify it, this study investigated the relationship between organizational climate and the work addiction of headquarters personnel at the Shahid Sadoughi University of Medical Sciences.

Methods: This descriptive-analytic study was conducted using stratified random sampling of 151 University employees in 2014. The data collection tool was an organizational climate questionnaire, which was supplemented by the Work Addiction Risk Test (WART). The data were analyzed using the Pearson test, Spearman test, independent t-test, Mann-Whitney test, one-way analysis of variance (ANOVA), and the KruskalWallis test using IBM-SPSS version 20.

Results: The findings of this study showed that the organizational climate was at a moderate level, and employees were in the danger level in terms of work addiction. In addition, among the dimensions of organizational climate, the risk dimension had a significant relationship with work addiction $(\mathrm{p}<0.05)$, and the dimensions of structure and responsibility were significantly different from occupational group and monthly salary $(p<0.05)$. Single employees showed a significant difference from married employees in the two dimensions of criteria and conflict $(\mathrm{p}<0.05)$.

Conclusion: Since the organizational climate score was low and the work addiction score was at the high-risk level, this issue demands more attention of senior managers and human resource officers of organizations to improve the organizational climate and increase employees' awareness of work addiction.

Keywords: work addiction, organizational climate, headquarters, personnel
\end{abstract}

\section{Introduction}

1.1. Background

Most individuals spend a lot of time working, and some spend far more time working than others (1). Many researchers consider workaholics to have an addiction, and they regard its theoretical foundation as being similar to other addictions, such as alcoholism (2). Work addiction occurs when too much time is spent on occupational

\section{Corresponding author:}

Mahan Mohammadi, Department of Health Care Management, School of Management and Medical Informatics, Isfahan University of Medical Sciences, Isfahan, Iran. Tel: +98.9131088493, E-mail: mahan_mo@hotmail.com Received: June 22, 2015, Accepted: October 22, 2015, Published: December 2015

iThenticate screening: August 17, 2015, English editing: August 26, 2015, Quality control: November 14, 2015

(C) 2015 The Authors. This is an open access article under the terms of the Creative Commons Attribution-NonCommercialNoDerivs License, which permits use and distribution in any medium, provided the original work is properly cited, the use is non-commercial and no modifications or adaptations are made. 
activities without any external obligation or pressure. In fact, there should be a distinction between being interested in and dedicated to one's work and work addiction. When people there are interested in and dedicated to their work, they enjoy their job and never get tired of it. Their interests and objectives are connected to their life goals, and they feel that they are successful in their occupation. Also, they believe that their personal objectives and the organization's objectives are consistent with each other (3).

\subsection{Statement of Problem}

Estimations show that about $30 \%$ of people in North America indicate that they are addicted to their work, and 53\% of them work more than 60 hours per week on average (4). The common characteristics of workaholics were investigated in early studies in this field by Scat et al., and three common features were identified among them, i.e., 1) they spend a lot of time on activities entrusted to them; in fact, they work hard; 2) they hardly ever leave work, and they think about their job, somewhat Obsessively, even when they are not at work; 3) they perform beyond the occupational responsibilities of their organization (2). Workaholics perform their work with higher standards, such as at a higher speed. However, this behavior could result in negative outcomes, such as burnout or feelings of intense pressure (5). In 2012, Bashan conducted a study on 347 managerial personnel in the automotive sector concerning the relationship between work addiction and job burnout. The findings of the study indicated that there was a positive relationship between work addiction and job burnout (6). Different studies have shown different and effective factors that contribute to the formation of work addiction. These factors include demographic features (such as age, gender, and occupation), environmental and work conditions, being dissatisfied with the current situation, values that govern the work environment, and the drive to improve one's own self-status (7). Along with the issue of work addiction, organizational climate is an important organizational concept that affects organizations' effectiveness and facilitates achieving the organizational objectives (8).

The dimensions of organizational climate include:

1) Structure: Feeling of personnel about the pressures of the organizational atmosphere, rules, policies, procedures, and tough administrative regulations;

2) Responsibility: The individuals could perform their job without being under the watchful eye of management;

3) Devotion: Sense of friendship and kindness in the work environment and developing informal and friendly groups;

4) Conflict: Tendency of managers and employees to hear opposing opinions and theories;

5) Rewards: Rewards that are directly determined according to the performance level of the individual and received by the personnel;

6) Risk taking: Feeling of challenge in the work and the organization;

7) Flexibility (individual creativity): the extent to which an individual feels there is no trend toward unnecessary rules.

8) Criteria: Regarding the objectives and performance criteria as important, emphasizing the correct performance of the task, challenges in individual and group objectives $(9,10)$.

\subsection{Objectives}

The general aim of this study was to investigate the relationship between work addiction and organizational climate among personnel at the Shahid Sadoughi University of Medical Sciences in 2014. The specific objectives of this study were as follows:

1) Determining the score of organizational climate governing the deputies of Shahid Sadoughi University of Medical Sciences, Yazd;

2) Determining the score of work addiction of the personnel working as deputies at Shahid Sadoughi University of Medical Sciences, Yazd;

3) Determining the relationship between organizational climate and the work addiction of managers, supervisors, and headquarters personnel at Shahid Sadoughi University of Medical Sciences;

4) Determining the amount of work addiction in managers, supervisors, and headquarters personnel at Shahid Sadoughi University of Medical Sciences based on the dimensions of organizational climate;

Determining the amount of work addiction in managers, supervisors, and headquarters personnel at Shahid Sadoughi University of Medical Sciences based on their demographic characteristics. 


\section{Material and Methods}

\subsection{Research Design and Sampling}

This cross-sectional study was conducted on managers, supervisors, and headquarters personnel at Shahid Sadoughi University of Medical Sciences in 2014. The sample size was calculated using pilot studies and computing coefficients $(r=0,25 ; \alpha=0.05 ; 1-\beta=0.8)$ and the formula $n=(Z 1-\alpha / 2+Z 1-\beta) 2+3 / C$. The sample size was calculated to be 125 respondents, but we included 151 respondents assuming there might be a $10-15 \%$ withdrawal rate. The respondents were selected through stratified random sampling among deputies at Shahid Sadoughi University of Medical Sciences, Yazd.

\subsection{Measurement Tool, Validity and Reliability}

Data related to organizational climate were collected using the standardized Litwin and Stringer questionnaire. This questionnaire is composed of 25 five-scale questions, and the respondents answered the short questions by choosing one of the following responses: 1- strongly disagree, 2-disagree, 3- neither disagree nor agree (null), 4- agree, and 5strongly agree. The reliability of organizational climate questionnaire was 0.92 based on the Cronbach's alpha test, and its validity was verified in a study conducted by Karimi et al. in 2010 (11). In the work addiction questionnaire (12), the test scores were divided into three classes, i.e., strongly workaholic, moderately workaholic, and nonworkaholic. People with an average score of 67-100 for work addiction were recognized as strongly workaholic. This means that they are subject to burnout. People with an average score of 57 to 66 were recognized as moderately workaholic, and there is hope these people can improve and prevent long-term, adverse consequences. People with an average score of 25 to 56 were deemed to not be workaholics. They are efficient employees and should not worry about possible negative effects of their work style on themselves or others. This questionnaire was composed of 25 four-scale questions that were to be answered as follows: 1- strongly disagree; 2- disagree; 3- agree; and 4- strongly agree. The validity of the work-addiction questionnaire was verified by Askari et al. (2). In a study of an industrial company in Isfahan such that Cronbach's alpha had a value of 0.92, which indicated that the measurement tool was highly reliable. The reliability of the Work Addiction Risk Test (WART), which is the oldest measurement tool and consists of a standardized questionnaire, was investigated in 1996 by Robinson, who verified its reliability.

\subsection{Ethical Considerations}

The Research Ethics Committee at Shahid Sadoughi University of Medical Sciences in Yazd approved this study, and, to protect the respondents' personal information, their names were not on the questionnaires. After some explanation about how to complete the questionnaire and after receiving oral consent from the people who were willing to participate in the study, the questionnaires were distributed to the respondents.

\subsection{Statistical Analysis}

The data were analyzed statistically using IBM-SPSS version 20. To analyze the data in this study at the descriptive statistics level, we used the mean and standard deviation, and, at the inferential statistics level, the Pearson correlation coefficient, Spearman test, independent t-test, Mann-Whitney, ANOVA, and the Kruskal-Wallis test were used.

\section{Results}

Among the 151 respondents in the study, 52.3\% were females and 47.7\% were males. Most of the respondents were married, with the $86.1 \%$ of the total. The age distribution was such that $42 \%$ of the respondents were between $26-30$ years old, 27.8\% were between 26 and 30, 25.2\% between 31 and 35, 25.2\% were between 36 and 45 and $15.9 \%$ were over 45 . The lowest sample size was related to the age group of less than 25 years old. In terms of total work experience, the highest percentage was for those who had 11-20 years of work experience (27.2\%). Those who had more than 20 years of work experience were the lowest percentage $(22.5 \%)$.In terms of occupational group distribution, employees made up the highest percentage, i.e., 94\%. The next group consisted of supervisors, who made up $3.3 \%$ of the total, and managers made up $2.6 \%$. In terms of the salaries that were received, $48.3 \%$ received between 143 to 286 dollar, $47.1 \%$ received between 143 to 514 dollar and $4.6 \%$ received salaries over 514 dollar. The findings showed that the average work addiction score of the respondents was 57.51. The highest percentage of the respondents $(47.1 \%)$ was in the second group i.e., the intermediate group, and $37.1 \%$ of the respondents were in non-workaholic group. The lowest percentage $(21.2 \%)$ was in danger level in terms of work addiction. Third-degree work addiction was the highest (28.6\%) in people between 26-30 years old and second-degree addiction was $50 \%$ in this age range. It should be noted that percentage of third-degree work addiction was zero in employees under 25 years old. Work addiction stage 2 and 3 were 46.8 and $22.8 \%$, respectively, in females, and, in both cases, females 
had higher percentages than males. Work addiction stage 3 was $21.5 \%$ among married respondents and $19 \%$ among those who were single. Work addiction stage 2 was $40.8 \%$ in married respondents and $47.6 \%$ in those who were single. Work addiction stage 3 was higher in people with 11-20 years of work experience. The highest percentage of work addiction stage $2(58.3 \%)$ was among employees with 6-10 years of work experience. Work addiction stage 2 and 3 had the lowest percentages in individuals with 20 years and or more of job experience $(32.5$ and $17.6 \%$, respectively). Work addiction stages 2 and 3 had the lowest percentages ( 0 and 14.3\%, respectively) among individuals with salaries over 514 dollar, and the percentages were the highest among individuals who had salaries of 286 to 514 dollar (23.9 and 43.7\%, respectively). Work addiction stage 2 and 3 had the highest percentages (60 and $40 \%$, respectively) among supervisors. The lowest rate of work addiction stage 2 and 3 was among managers (25\%) and employees (20.4\%). Table 1 indicates that the average score of organizational climate was $2.98 \pm 0.49 \%$. Among the dimensions of organizational climate, the highest average score $(3.29 \pm 0.47)$ was related to criteria, followed by risk, conflict, responsibility, devotion, and structure dimensions. The lowest average of the organizational climate dimension was related to reward $(2.72 \pm 0.51)$.

Table1. Descriptive statistics of organizational climate and its dimension among study population

\begin{tabular}{|l|l|l|l|l|}
\hline Variables & Max & Min & S.D & Mean \\
\hline Structure & 4 & 1.50 & 0.44 & 2.75 \\
\hline Responsibility & 4 & 2 & 0.36 & 2.95 \\
\hline Risk & 4.67 & 2 & 0.51 & 3.23 \\
\hline Bonus & 4.38 & 1.50 & 0.51 & 2.72 \\
\hline Devotion & 4.20 & 1 & 0.61 & 2.82 \\
\hline Conflict & 4.67 & 1.67 & 0.58 & 3.10 \\
\hline Criteria & 4.67 & 1.44 & 0.47 & 3.29 \\
\hline Organizational climate & 4.37 & 1.58 & 0.49 & 2.98 \\
\hline
\end{tabular}

Table 2 shows the average of the organizational climate dimension for each deputy at Shahid Sadoughi University of Medical Sciences in Yazd. According to the Kolmogorov-Smirnov test, the three dimensions of devotion, risk, and conflict were not distributed normally. Therefore, non-parametric tests were used to analyze these three variables. In terms of the risk dimension, the Food and Drug Deputy obtained the highest average (3.39), and the Deputy of Education obtained the lowest average (3.11). In terms of the reward dimension, the Deputy of Health and the Deputy of Research obtained the highest and lowest average scores, i.e., $2.96 \pm 0.58$ and $2.54 \pm 0.59$, respectively. In terms of devotion, the Deputy of Health had the highest average (3.06 \pm 0.46$)$, and the Deputy of Education had the lowest average $(2.4 \pm 0.57)$. In terms of structure, the Deputy of Health and the Deputy of Education had the highest and lowest averages, i.e., $3 \pm 0.46$ and $2.50 \pm 0.31$, respectively. In terms of responsibility, the Deputy of Culture and the Deputy of Education had the highest and lowest averages, i.e., $3.04 \pm 0.35$ and $2.84 \pm 0.29$, respectively. In terms of conflict, the Deputy of Culture and the Deputy of Health had the highest and lowest averages, i.e., $3.33 \pm 0.64$ and $3 \pm 0.41$, respectively. In terms of criteria, the Deputy of Research and the Deputy of Education had the highest and lowest averages, i.e., $3.58 \pm 0.54$ and $3.05 \pm 0.53$, respectively. The findings showed that work addiction was only correlated to the risk dimension of organizational climate $(\mathrm{p}=0.002, \mathrm{r}=0.24)$. The chisquared test revealed that work addiction is not related to demographic features of respondents. In addition, results of Kruskal-Wallis test revealed that among organizational climate dimensions, different occupational groups were significantly different in terms of structure $(\mathrm{p}=0.001)$. According to the Tukey test, employees and managers were significantly different in terms of structure $(\mathrm{p}=0.001)$. Furthermore, supervisors with managers represented significant difference in terms of structure $(\mathrm{p}=0.01)$. People with different salaries showed significant difference in terms of responsibility as well $(\mathrm{p}=0.01)$. According to the Tukey test, individuals with salary of 143 to 514 dollar showed significant difference in terms of responsibility dimension with individuals with the salary of 286 to 514 dollar ( $p=0.01$ ). Deputies of the Shahid Sadoughi University of medical sciences showed significant difference in terms of criteria $(p=0.02)$. According to the Tukey test, deputies of education and research showed significant difference with each other among deputies. Individuals with different occupational group were significantly different in terms of devotion; according to the Tukey test, it was revealed that there is a significant difference between managers and employees in terms of devotion. Marital status showed significant difference among single and married individuals in such a way that single individuals were significantly different from married ones in terms of criteria and conflict $(\mathrm{p}<0.05)$. 
Table2. Organizational climate in Shahid Sadoughi University of Medical Sciences

\begin{tabular}{|c|c|c|c|c|c|c|c|}
\hline \multirow[t]{2}{*}{ Deputy (department) } & \multicolumn{7}{|c|}{ Dimension of organizational climate } \\
\hline & Criteria & Conflict & Responsibility & Structure & Devotion & Bonus & Risk \\
\hline Treatment & $3.27 \pm 0.56$ & $\begin{array}{l}2.93 \pm \\
0.57\end{array}$ & $3.04 \pm 0.28$ & $\begin{array}{l}2.63 \pm \\
0.51\end{array}$ & $\begin{array}{l}2.71 \pm \\
0.72\end{array}$ & $2.78 \pm 0.48$ & $\begin{array}{l}3.14 \pm \\
0.51\end{array}$ \\
\hline $\begin{array}{l}\text { Logistics and } \\
\text { Personnel Affairs }\end{array}$ & $3.18 \pm 0.42$ & $\begin{array}{l}3.02 \pm \\
0.61 \\
\end{array}$ & $2.92 \pm 0.39$ & $\begin{array}{l}2.71 \pm \\
0.45 \\
\end{array}$ & $\begin{array}{l}2.82 \pm \\
0.65 \\
\end{array}$ & $2.68 \pm 0.49$ & $\begin{array}{l}3.2 \pm \\
0.59 \\
\end{array}$ \\
\hline Food and Drug & $3.42 \pm 0.45$ & $\begin{array}{l}2.98 \pm \\
0.53 \\
\end{array}$ & $2.94 \pm 0.33$ & $\begin{array}{l}2.65 \pm \\
0.33\end{array}$ & $\begin{array}{l}2.92 \pm \\
0.33 \\
\end{array}$ & $2.63 \pm 0.52$ & $\begin{array}{l}3.39 \pm \\
0.41 \\
\end{array}$ \\
\hline $\begin{array}{l}\text { Health and Disease } \\
\text { Prevention }\end{array}$ & $3.53 \pm 0.37$ & $\begin{array}{l}3.20 \pm \\
0.41\end{array}$ & $2.88 \pm 0.46$ & $3 \pm 0.46$ & $\begin{array}{l}2.62 \pm \\
0.46\end{array}$ & $2.96 \pm 0.58$ & $\begin{array}{l}3.2 \pm \\
0.31\end{array}$ \\
\hline $\begin{array}{l}\text { Cultural and Student } \\
\text { Affairs }\end{array}$ & $3.28 \pm 0.46$ & $\begin{array}{l}3.32 \pm \\
0.64 \\
\end{array}$ & $3.04 \pm 0.35$ & $\begin{array}{l}2.84 \pm \\
0.41\end{array}$ & $\begin{array}{l}3.01 \pm \\
0.53 \\
\end{array}$ & $2.73 \pm 0.49$ & $\begin{array}{l}3.31 \pm \\
0.54\end{array}$ \\
\hline Education & $3.05 \pm 0.53$ & $\begin{array}{l}3.13 \pm \\
0.52\end{array}$ & $2.84 \pm 0.29$ & $\begin{array}{l}2.77 \pm \\
0.47\end{array}$ & $\begin{array}{l}2.63 \pm \\
0.57 \\
\end{array}$ & $2.79 \pm 0.52$ & $\begin{array}{l}3.11 \pm \\
0.43\end{array}$ \\
\hline Research & $3.58 \pm 0.54$ & $3 \pm 0.52$ & $2.98 \pm 0.35$ & $\begin{array}{l}2.50 \pm \\
0.31\end{array}$ & $\begin{array}{l}2.71 \pm \\
0.48 \\
\end{array}$ & $2.54 \pm 0.59$ & $\begin{array}{l}3.22 \pm \\
0.57\end{array}$ \\
\hline
\end{tabular}

\section{Discussion}

The aim of this study was to investigate the relationship between work addictions of managers, supervisors, and headquarters personnel of Shahid Sadoughi University of Medical Sciences with organizational climate. The findings showed that the work addiction score of the sample under study was $57.51 \pm 11.22$, which reveals that individuals under study were moderately workaholic, and it is stated that they could prevent the long-term consequences of this stage of work addiction through improving their behavior. Previous studies have shown that demographic feature, stressful work environment, and organizational culture in which high work pressure is regarded as a value, are related to work addiction (1). In the current study, no significant relationship was observed between work addiction and the demographic features of respondents. In the study by Akin \& Ugaz in 2010 with 227 teachers to determine the relationship between the tendency toward work addiction and the level of burn out, it was revealed that the tendency toward work addiction was not different in terms of gender, but, in terms of age, there was a difference (6). In addition, Bardak \& Baloğlu, in their study in 2012, showed that the tendency toward work addiction among school managers was not different in terms of gender, education, and marital status, but they were different in terms of age, seniority, and elapsed time at work (6). In the study by Aziz \& Cunningham with 199 full-time laborers about the relationship between the role of gender in work addiction, work stress, and imbalance in life, it was concluded that there is a positive correlation between work addiction and gender; however, work addiction was not related directly to work stress and imbalance in work and life (6). In 2001 Maume and Bellas in Ohio realized that, if individuals receive extra salary, they would work much longer and harder. In addition, family requirements would cause them to work more. It even was observed that individuals with higher education who have professional careers in large, reputable companies are greatly prone to become workaholics (13). In 2010, Zaree and Jamshidi, in a study conducted to investigate work addiction among nurses at the hospitals in Mazandaran Province, concluded that, in general, work addiction is higher among male nurses than female nurses, and they consider higher salary and benefits as the main cause of working more (14). The results of this section did not conform to some other studies, probably because of the difference in the samples that were studied. The average organizational climate score was $2.98 \pm 0.49$, which showed that the organizational climate of the deputies at Shahid Sadoughi University of Medical Sciences is not at an appropriate level (2.98 is less than the mean of 3 ). In the study by Ekrami et al., the average score of organizational climate was $2.24 \pm 0.34$ for the headquarters personnel at the Ministry of Jihad Agriculture (15). In the study by Dargahi et al., most personnel were unhappy with the organizational climate of the hospitals under study (16). The lowest and highest average of organizational climate dimensions was related to the reward $(2.72 \pm 0.51)$ and criteria $(3.29 \pm 0.47)$ dimensions. The low average score of reward means that the organization should strengthen its motivators; the individual's feeling about being rewarded for good performance and fair payment is not at an appropriate level. In this regard, Nicepeyma and Gholamnejad concluded that the main negative factors that affect the views of nurses in Tehran about organizational climate include lack of reward and persuasion, disproportionate workload, and lack of participation in the main decisions of the ward. In addition, the main positive factors were having enough information to perform their work, good relationships, their colleagues 'support, and good relationships with the head of the ward (17). The higher value of 
the criteria relative to other sub scales of organizational climate indicates that respondents regard objectives and criteria of organization's performance as important and they emphasize correct performance of their work. In this study, no significant relationship was observed between organizational climate and its dimensions with demographic features. Only the two dimensions of structure and responsibility showed significant difference with occupational group and salary of the respondents. Contrary to the present study, Dargahi et al. showed that organizational climate of the hospitals that they have studied represented a significant relationship with age, type of career of the personnel, and employment status (16). Sadeghi and Fathi, in their study investigating the organizational climate of schools, concluded that there was a significant relationship between teachers' gender and organizational climate (18). About the relationship between organizational climate and work addiction, there only was a significant relationship between the risk dimension and work addiction. To improve the structure dimension, it is suggested that careers be defined clearly and that stringent administrative regulations be minimized. To improve the responsibility dimension, managers should give the right of decision making and the authority to take action to personnel. To improve the reward dimension of organizational climate, personnel should be promoted according to their qualifications. To improve the risk dimension, managers should utilize useful suggestions of personnel and encourage them to take timely and calculated risks. To improve the devotion and support dimension, managers should organize meetings for becoming more familiar with their personnel, avoid having a hostile environment, avoid unhealthy competition among personnel, improve their relationships with personnel, support individuals when they make a mistake, and take individuals' feelings and needs into consideration. To improve the other dimensions of organizational climate, including standard atmosphere, conflict and identity, it is required that managers prioritize conformity with standards and emphasize the improvement of personal and group performance (11).

Among the limitations of this study, the study domain of this research was the headquarters of the Shahid Sadoughi University of Medical Sciences, and the results could not be generalized to other industries or service companies, since challenges and the factors that affect industries are different. This study was limited to the investigation of the effect of organizational climate on work addiction in Yazd city. Therefore, it would not be appropriate to generalize its results to other cities, provinces, or countries; second, the questionnaires were based on self-reports, and this increases the possibility of measurement errors. Therefore, it is necessary to conduct additional studies of the main variables of the research and to conduct studies using other methods for collecting data to ensure that the results can be generalized.

\section{Conclusions}

The results of this study showed that work addiction of headquarters personnel at the Shahid Sadiughi University of Medical Sciences was moderate, and the organizational climate score was moderate as well. In addition, risk taking, which is a dimension of organizational climate, could affect work addiction among the personnel. The practical importance of these findings is that they could significantly reduce emerging, undesirable, organizational behaviors that are mostly related to personnel behavior. It appears that, by reinforcing the risk-taking dimension, in the headquarters units at Shahid Sadoughi University of Medical Sciences in Yazd, the possibility of addictive behaviors emerging could be decreased. It is suggested that systematic rewards be provided in response to the low value of the reward dimension in the organizational climate that was investigated. The following items could be effective in reducing the emergence of work addiction behaviors, i.e., recognizing personnel with signs of work addiction, evaluating the value of work addiction, establishment of work priorities, providing alternative career plans, making sure that personnel leave work at the specified time, providing training courses, and creating an organizational culture with values that emphasize the importance of an appropriate balance between work, family, and other activities.

\section{Acknowledgments:}

This study was the result of research No. 3228, approved by the Research Center for Hospital Management at Shahid Sadoughi University of Medical Sciences in Yazd. The authors of this paper appreciate the contributions of the members of the Research Center and all other personnel who participated in this study.

\section{Conflict of Interest:}

There is no conflict of interest to be declared.

Authors' contributions:

All authors contributed to this project and article equally. All authors read and approved the final manuscript. 


\section{References}

1) Van Wijhe C, Peeters M, Schaufeli W; Irrational beliefs at work and their implications for workaholism. J Occup Rehabil. 2013; 23(3): 336-46. doi: 10.1007/s10926-012-9416-7. PMID: 23307116.

2) Askari A, Nouri A; Investigating the Relationship between Workaholic and Dimensions of General Health in the Employees of an Organization in Isfahan. Iran Occupational Health. 2011; 8 (2):14-0.

3) Enayati G-r, Shekari G-a, Tahmasbi R, Ghaffari H, Shabani M; The Relationship between Workaholism and Organizational Commitment. Quarterly Journal of Management and Development Process. 2012; 25(1): 93-114.

4) Golden L; Distinctions between Overemployment, Overwork, Workaholism and Heavy Investments in Work Time. Harpaz and Snir book, Heavy Work Investment; 2014. Doi: 10.2139/ssrn.2371082 .

5) De Carlo NA, Falco A, Pierro A, Dugas M, Kruglanski AW, Higgins ET; Regulatory mode orientations and well - being in an organizational setting: the differential mediating roles of workaholism and work engagement. J Appl Soc Psychol. 2014; 44(11): 725-38. doi: 10.1111/jasp.12263.

6) Zincirkiran M. Workaholism Research on Junior Administrative Police Officers in the Police Department; Int J Acad Res Bus Soc Sci. 2014; 4(3): 445-56. doi: 10.6007/IJARBSS/v4-i3/727.

7) Ahmadi P, Tahmasebi R, Babashahi J, Fattahi M; The Role of personality factors in work holism formation. TRANSFORMATIONAL MANAGEMENT JOURNAL. 2010; 2(3): 46-67.

8) Alipour FH; The relationship between organizational climate and communication skills of managers of the Iranian physical education organization. Procedia Soc Behav Sci. 2011; 30: 421-8. doi: 10.1016/j.sbspro.2011.10.083.

9) Nazem F, Parsi F; The Relationship between Organizational Climate and Productivity of the Managers in Emam Khomaini Emdad Committee in order to provide a suitable pattern for Management. Quarterly Journal of Educational leadership \& Administration. 2010; 4(3): 127-47.

10) Permarupan PY, Saufi RA, Kasim RSR, Balakrishnan BK; The Impact of Organizational Climate on Employee's Work Passion and Organizational Commitment. Procedia Soc Behav Sci. 2013;107: 88-95. doi: 10.1016/j.sbspro.2013.12.403.

11) Karimi M, Rajaeepur S, Hovida R. A study of the relationship between organizational climate and ethical behaviors among the administrative personnel of Isfahan University and Isfahan Medical Sciences University. Quarterly Journal of Educational leadership \& Administration. 2010; 4(1): 83-102

12) Mirza CS. Positive and Negative Workaholism: University of Houston; 2012.

13) Maume DJ, Bellas ML; The overworked American or the time bind? Assessing competing explanations for time spent in paid labor. American Behavioral Scientist. 2001; 44(7): 1137-56. doi: $10.1177 / 00027640121956692$.

14) Zaree Matin H, Jamshidi Kohsari H; The Survey of Iranian Nurses' Workaholism Based on Gender Difference. Journal of Organizational Culture Management. 2010; 8(21): 133-57.

15) Ekrami M, Zaker Khatibani MM, Ferdosi N; Anticipating of Organizational Commitment Based on Personnel's Beliefs in the Organizational Environment. Quarterly Journal of Management and Development Process. 2008; 21(1): 89-105.

16) Dargahi H, Musavi M, Shaham G, Molai zadeh A; Organizational Climate of Hospitals at Tehran University of Medical Sciences. Journal of Health Administration. 2013; 15(50): 31-40.

17) Nicpeyma N, Gholamnejad H; Influencing Factors on Hospital Nurses' Perspectives about Different Dimensions of Organizational Climate. J Facul Nurs Midwifery. 2010;16(2):72-8.

18) Sadeghi A, Fathi B; Investigate the relationship between organizational climate and job satisfaction of teachers in the Masal city of Gilan province. Humanit Soc Sci. 2003; 2(5). 